\title{
Cross-Sectional Analysis of Nutritional Status, Knowledge and Uptake of Nutritional Services Among Adolescent Girls in Western India
}

\author{
Somen Saha (D) \\ Apurvakumar Pandya (D) ${ }^{2}$ \\ Yogini Kandre' \\ Devang Raval' \\ Deepak Saxena (D' \\ 'Department of Public Health, Indian \\ Institute of Public Health, Gandhinagar, \\ Gujarat, India; ${ }^{2}$ Parul Institute of Public \\ Health, Parul University, Vadodara, \\ Gujarat, India
}

Purpose: Malnutrition status of adolescent girls remains a major public health problem in India. The present study assessed nutritional status, associated factors contributing to malnutrition and their access to health-care services in Dev Bhumi Dwarka district of Gujarat situated in western part of India.

Materials and Methods: The study was carried out using descriptive cross-sectional design. A total of 1252 adolescent girls from all four blocks of Dev Bhumi Dwarka district were interviewed by field investigators. The data were collected on socio-demographic characteristics, physical activities, diet, and anthropometry. The WHO classification for body mass index (BMI) was used to assess underweight, overweight, and obesity among adolescent girls. Chi-square analyses were performed to identify significant determinants of under-nutrition.

Results: Mean age of the study population was $13.82 \pm 2.31$. Of the total, around $34 \%$ of the adolescent girls were out-of-school. The prevalence of underweight $(<-2 \mathrm{SD})$ was $19.6 \%$, $8.9 \%$ were overweight, and $2.6 \%$ were obese. The mean BMI was $19.77 \pm 2.42 \mathrm{~kg} / \mathrm{m}^{2}$, and height was $149.15\left(2.23 \mathrm{~m}^{2}\right)$. In terms of knowledge, almost $79.6 \%$ were unaware of irondeficiency anaemia, about $70 \%$ were not aware of haemoglobin test, and $44 \%$ did not know the benefit of using sanitary napkins. In addition, uptake of nutritional and health services was limited. The study found a statistically significant association of age $(p=0.00)$, the number of family members $(p=0.016)$, knowledge $(p=0.05)$, and use of toilet $(0.041)$ with low-BMI.

Conclusion: Existing nutritional interventions need to focus on nutrition, health and hygiene education. It also reinforces a need for implementation research to understand barriers in uptake of health and nutrition services.

Keywords: adolescent nutrition, malnutrition, Gujarat, India

\section{Introduction}

Globally, adolescents constitute one-fifth of the total global population. ${ }^{1,2}$ About $87 \%$ of adolescents reside in developing countries ${ }^{2}$ and India shares largest adolescent population with 243 million adolescents, which is $21 \%$ of the whole Indian population. ${ }^{3}$ This young population - people aged between 10 and 19 years - is a crucial group for addressing diverse health needs and protecting future generation from diseases.

The adolescence phase - transition from childhood to adulthood - is marked with rapid and intense physiological, psychological and sexual growth. ${ }^{4}$ It is also a time for growth spurts and increased physical activities. ${ }^{5-7}$ As a result, adolescents need more
Correspondence: Somen Saha Department of Public Health, Indian Institute of Public Health, Opp. Air Force Headquarter, Gandhinagar-Chiloda Highway, Near Lekawada Bus Stop, Gandhinagar, Gujarat, India

Tel +9l-968-7207549

Email ssaha@iiphg.org 
nutrients compared to adults. Inadequate nutrition can lead to delayed sexual development and slower linear growth. ${ }^{8,9}$ Malnutrition - either nutrition deficiency (underweight) or excess nutrition (over-weight or obesity) - leads to physical as well mental health problems in adolescents. ${ }^{10,12}$ For example, adolescents with nutrition deficiencies are likely to face short physique, cognitive impairment, mental functioning and reduced immunity whereas overweight and obese adolescents often experience low self-esteem, distorted body image and are at higher risk for developing noncommunicable diseases including mental disorders. ${ }^{710-12}$ Malnutrition has even more devastating effects on adolescent girls. In addition to common health risks, adolescent girls are more susceptible to infections, face difficulties in recovering from illnesses and surviving child birth in future or more likely to deliver low birthweight babies creating a vicious cycle..$^{8,11-14}$

In India, malnutrition in adolescent girls is a big challenge. According to $\mathrm{UNICEF},{ }^{13} 56 \%$ of girls are affected with anaemia - a form of malnutrition. The National Family Health Surveys reported that about $41.9 \%$ adolescent girls were underweight while $4.2 \%$ girls were overweight ${ }^{15}$ whereas about $57.2 \%$ women in the age group of $15-49$ years (including adolescent girls) were anaemic. ${ }^{16}$ Addressing the burden of malnutrition among adolescent girls is important to support effective interventions to achieve the Sustainable Development Goal of ending malnutrition by 2030. ${ }^{12,17}$

Despite numerous health programs addressing adolescent health, accessibility and utilization of these programs remain problematic. ${ }^{10,16-18}$ Furthermore, studies on adolescent malnutrition are limited in the context of Gujarat state and minimal reliable data on adolescent nutrition available in Dev Bhumi Dwarka district - a district separated from the Jamnagar District on August 15th, 2013. Considering the new district, formative studies around public health and nutrition that inform program implementation is in an infancy stage. In view of these, the present study aimed at assessing nutritional status, access to nutritional and health services and factors associated with under-nutrition in adolescent girls from the Dev Bhumi Dwarka district of Gujarat state in Western India.

\section{Materials and Methods Study Design}

Between February to March 2020, a descriptive crosssectional, community-based survey of adolescent girls was conducted.

\section{Study Sites}

The present study was conducted in 249 villages of all four blocks of the Dev Bhumi Dwarka district, namely, Khambhaliya, Bhanvad, Kalyanpur, and Dwarka.

\section{Sample Size}

Based on the adolescent population in the district, the sample size was calculated using Open Epi. Considering $20 \%$ non-response rate with a relative allowable error of $15 \%$ and design effect of 1 at $95 \%$ significance level and alpha risk of $5 \%$, the calculated sample size was 1300 . The same size was calculated using the formula: $N=Z p(1-p) / D$ [Where $\mathrm{p}$ is prevalence and $\mathrm{D}$ is absolute precision $(\mathrm{Z}=$ 1.96)]. We achieved 1252 sample size for the study.

\section{Variables}

Age, education, schooling status (school-going, nonschool going), caste, religion, blocks (geographic locations), knowledge, uptake of nutrition and health services (such as receipt of Iron Folic Acid tablets, take-home ration and counselling from anganwadi centers), hygiene and sanitation (usage of toilet facility) practices were considered as independent variables for the study. Nutritional status as per the World Health Organization classification was dependent variable.

\section{Study Instrument}

The survey instrument was developed based on the review of previous national surveys in India ${ }^{15,16,28}$ and the published literature on adolescent nutrition. ${ }^{20,22-24,34-36}$ Detailed information on the socio-demographic of the beneficiaries, practices related to general hygiene, access to integrated child development and health services were collected using a pretested and validated questionnaire. Nutritional status was assessed using standard methods for anthropometry. Using a PRESTIGE HM007 mobile stadiometer (measuring range 20-205 cm), we measured adolescent girls' height and their weight was measured using a PRESTIGE 150 digital scale (weight capacity $150 \mathrm{~kg}$, division 100g). The World Health Organization classification was used for the assessment of malnutrition. ${ }^{19}$

Field investigators were trained on survey tool, interview method and anthropometry. They participated in a standardization exercise with 20 adolescent girls to assess Technical Error of Measurement. The inter-observer coefficient of reliability was 0.93 for height and 0.97 for weight. 


\section{Data Collection}

Field investigators visited sampled households in all villages of the study area and interviewed adolescent girls using survey tool. After interview, height was measured using mobile stadiometer and weight was measured on a digital scale, both of which were carried to the field by investigators. For accuracy, measurements were taken twice and mean of the two measurements were calculated. We then calculated BMI. Age was calculated based on the participants' date of birth taken from birth card.

\section{Data Analysis}

The data were analyzed using SPSS software (version 20). The continuous variables were summarized using frequency, percentage, and mean with standard deviation (SD). For categorical variables, Chi-square test of independence was performed to identify significant determinants of malnutrition.

\section{Ethical Considerations}

Formal approval was sought from the state and the district authorities. We also sought consent for each village's participation in the study from the Sarpanch, who is an elected representative and head of Panchayati Raj Institute - a local governance institution in the village. Field investigators explained the purpose of the study and processes to all adolescent girls and any parents. Adolescent girls were informed that their participation was voluntary, non-participation in the study would not disadvantage the family or adolescent in any way, and that they could stop the interview at any time or skip any questions they did not want to answer. Written informed consent from one of the parents or guardians and written assent from the adolescent girls were obtained.

This study was conducted in accordance with the Declaration of Helsinki. Ethical approval was obtained from the Institutional Ethics Committee of the Indian Institute of Public Health Gandhinagar. All data collected were anonymized, and kept in personal computer protected with password.

\section{Results}

Of the total 1252 adolescent girls, more than half (57.9\%) of them were in the age range between 10 and 14 years of age, whereas the rest of them (42\%) were aged between 15 and 19 years. The mean age was $13.8 \pm 2.31$. Nearly half $(47 \%)$ of the participants had completed secondary education $(8$ years of schooling), $42 \%$ of them had completed primary education ( 5 years of schooling) and about $4 \%$ had no formal education. More than a quarter (34.2\%) were out-of-school while $66 \%$ of them were school-going. Table 1 presents the demographic characteristics of the study population.

\section{Knowledge About Health and Nutrition}

Table 2 presents participants' responses on adolescent girls' knowledge about health and nutrition. Almost fourfifths of the participants $(79.6 \%)$ had not heard about irondeficiency anaemia. Thus, most of them were unaware of the signs and symptoms of anaemia. Moreover, $68 \%$ did not know about malnutrition. Knowledge related to menstrual hygiene was also poor. About $44 \%$ did not know the benefit of using sanitary napkins and about $40 \%$ of them reported the use of sanitary napkins during menstruation.

\section{Practice Related to General Hygiene}

Results show variability in handwash practices. Participants reported handwash practices before and/or after critical incidents such as before preparing food, feeding a child, after latrine, cleaning home, etc.; however, only $17 \%$ of them followed handwash in all critical incidents as shown in Table 3. Most participants (87\%) reported washing their hands with soap. Notably, $80 \%$ of

Table I Demographic Characteristics (I252)

\begin{tabular}{|l|l|}
\hline Demographic Characteristics & Study Participants \\
\cline { 2 - 3 } & N (\%) \\
\hline Age & $725(57.9)$ \\
\hline I0-14 (Early Adolescence) & $527(42)$ \\
\hline I5-19 (Late Adolescence) & $13.8 \pm 2.31$ \\
\hline Mean Age & \multicolumn{2}{|l}{} \\
\hline Education & $50(4.0)$ \\
\hline Illiterate & $521(41.6)$ \\
\hline Primary & $587(46.9)$ \\
\hline Secondary & $93(7.4)$ \\
\hline Higher Secondary & $1(0.8)$ \\
\hline Graduation & $824(65.8)$ \\
\hline School status & $428(34.2)$ \\
\hline Presently school-going & \multicolumn{2}{|l}{} \\
\hline Out-of-school & \\
\hline
\end{tabular}


Table 2 Awareness About Anaemia Among Adolescent Girls $(\mathrm{N}=1252)$

\begin{tabular}{|c|c|}
\hline Variables & $\mathbf{N}(\%)$ \\
\hline \multicolumn{2}{|c|}{ Heard about Iron-deficiency Anemia } \\
\hline Yes & $255(20.4)$ \\
\hline No & 997 (79.6) \\
\hline \multicolumn{2}{|c|}{ Knowledge about signs and symptoms of Anemia } \\
\hline Weakness & $145(\mid 1.6)$ \\
\hline Pale skin & $85(6.8)$ \\
\hline Fatigue & I0I (8.I) \\
\hline Giddiness & $105(8.4)$ \\
\hline Lethargy & $69(5.5)$ \\
\hline \multicolumn{2}{|c|}{ Knowledge about haemoglobin test } \\
\hline Yes & $369(29.5)$ \\
\hline No & $883(70.5)$ \\
\hline \multicolumn{2}{|c|}{ Knowledge about malnutrition } \\
\hline Know & $178(14.2)$ \\
\hline Partially know & $218(17.4)$ \\
\hline Do not know & $856(68.4)$ \\
\hline
\end{tabular}

Table 3 Practice Related to General Hygiene $(\mathrm{N}=1252)$

\begin{tabular}{|l|l|}
\hline Variables & N (\%) \\
\hline Handwash Practices & $214(17.10)$ \\
\hline In all critical incidents & $1030(82.3)$ \\
\hline Before preparing food & $558(44.6)$ \\
\hline Before feeding a child & $1062(84.8)$ \\
\hline After using toilets & $460(36.7)$ \\
\hline After handling cattle & $924(73.8)$ \\
\hline After cleaning or mopping & 38 I (30.4) \\
\hline After feeding a child & \multicolumn{2}{|l|}{} \\
\hline Substance Used for Handwashing & $1094(87.4)$ \\
\hline Handwash with soap & I55 (12.4) \\
\hline Handwash with plain water with/without Ash & $1005(80.3)$ \\
\hline Household Access to Toilet & \\
\hline Have toilet at home &
\end{tabular}

Table 4 Nutritional and Health Services Availed by the Adolescent Girls (N = 1252)

\begin{tabular}{|l|l|}
\hline Services & N (\%) \\
\hline Weighing & $788(62.9)$ \\
\hline Counselling & $644(51.4)$ \\
\hline Take Home Ration & $594(47.4)$ \\
\hline Iron Folic Acid and Calcium Tablets & 54 I (43.2) \\
\hline Double Fortified Salt & $373(29.8)$ \\
\hline
\end{tabular}

participants stated to have a toilet at home and most of them $(79.5 \%)$ use the toilet for defection.

\section{Uptake of Nutritional and Health Services} Anthropometric measurement on Mamta Diwas was acknowledged only by $43 \%$ of adolescent girls. As shown in Table 4, nearly $62.9 \%$ participants reported being checked for weight followed by counselling (51.4\%), take-home ration (THR) (47.4\%), and IFA \& Calcium tablets (43.2\%). Of those receiving THR, 77\% of them reported receiving 1-2 packets, less than the prescribed guideline of 4 packets of THR per month.

While asking health-insurance-related questions, $78.4 \%$ of them denied having any Government health insurance scheme. Out of those who had health insurance (21.6\% of the total), $18.8 \%$ had Maa Antyodaya Card, whereas a small percentage of the population had $(2.2 \%)$ Prime Minister Jan Arogya Yojana.

\section{Body Mass Index (BMI)}

BMI of adolescents was classified using WHO BMI standards for the Asia-Pacific population. ${ }^{19}$ As noted in Table 5, not all participants agreed to anthropometric measurements; hence, we could gather anthropometric data for the 1240 sample. As per Classification, about

Table 5 Grades of BMI for Age in Adolescent Girls According to WHO Asia Pacific Criteria $(n=1240)$

\begin{tabular}{|l|l|}
\hline Weight for Age & N (\%) \\
\hline Underweight $\left(<18.5 \mathrm{~kg} / \mathrm{m}^{2}\right)$ & $243(19.6)$ \\
\hline Normal Weight $\left(18.5-22.9 \mathrm{~kg} / \mathrm{m}^{2}\right)$ & $854(68.9)$ \\
\hline Overweight $\left(23.0-24.9 \mathrm{~kg} / \mathrm{m}^{2}\right)$ & $110(8.9)$ \\
\hline Obese $\left(\geq 25.0 \mathrm{~kg} / \mathrm{m}^{2}\right)$ & $33(2.6)$ \\
\hline
\end{tabular}


$19.6 \%$ of participants had low BMI (<-2SD), 8.9\% were overweight, and $2.6 \%$ were obese. The overall mean weight of the study population was $40.39 \pm 9.84 \mathrm{kgs}$ with a range being $17.2 \mathrm{kgs}$ to $85.5 \mathrm{kgs}$, and the mean height was $149.18 \pm 9.63 \mathrm{~cm}$ with a range minimum being $100.00 \mathrm{~cm}$ to a maximum of $189 \mathrm{~cm}$.

In the present study, participants in early adolescence (10 and 14 years) and late adolescence (15 to 19 years) reported low BMI. However, mean height, weight, and BMI were less among the participants aged between 10 and 14 years $\left(144.18,28.4,13.7 \mathrm{~kg} / \mathrm{m}^{2}\right.$, respectively) than 15 to 19 years $\left(149.19,40.34,14.9 \mathrm{~kg} / \mathrm{m}^{2}\right)$. Participants between the ages of 10 and 14 years were more underweight $(64.62 \%)$ than 15 to 19 years $(35.84 \%)$. A chisquare test of independence showed significant association between age and underweight, $X^{2}(121.87, \mathrm{~N}=1240)=$ $10.33, \mathrm{p}=0.0002$.

The association of age $(p=0.00)$, number of family members $(p=0.016)$, knowledge $(p=0.05)$, and use of toilet (0.041) with BMI categories was statistically significant. Table 6 depicts the association of socio-demographic parameters with BMI categories.

\section{Discussion}

It is well acknowledged that nutritional status of adolescent girls is an important determinant of health outcomes. ${ }^{2,4,8,10-12}$ Hence, it is important to improve nutritional status of adolescent girls.

More than half of girls (57.9\%) in our study population belonged to the category of early adolescence phase (10 14 years of age) and nearly half (42.0\%) were late adolescence phase (15-19 years of age). The study revealed that more girls in the early adolescence phase had low BMI (64.62\%) compared to girls in the age group of 15 to 19 years $(35.84 \%)$ based on WHO standards. These findings are similar to earlier studies. ${ }^{21-23}$

In the present study, more than a quarter $(34.2 \%)$ of the adolescent girls were out-of-school, and about $4 \%$ of adolescent girls had no formal education. Educational status was not significantly associated with underweight among adolescent girls, which was not in sync with an earlier study conducted in Maharashtra and Pondicherry, ${ }^{12,24}$ secondary analysis of the National Family Health Survey $4^{25}$ and a recent study conducted in Northern Ethiopia ${ }^{26}$ and South West Ethiopia. ${ }^{27}$

About $19.6 \%$ of adolescent girls had low BMI $(<-2 \mathrm{SD})$. This prevalence is lower than the prevalence of underweight in Gujarat (28.5) and the national average
(28.9\%) reported in CNSS report. ${ }^{28}$ A study conducted in rural Gujarat by Trivedi et al in $2016^{29}$ reported undernutrition was in nearly half of the sample (46.3\%). Similarly, studies conducted in West Bengal, ${ }^{30}$ Himachal Pradesh, ${ }^{14}$ Maharashtra, ${ }^{31}$ Assam ${ }^{23}$ reported higher prevalence of underweight $(49 \%, 33 \%, 55 \%, 49.4 \%)$. Some studies conducted in developing countries ${ }^{24,26,27,34,35}$ also reported a higher prevalence of underweight among adolescent girls. These studies were conducted at different times using different standards with different cut-off points to assess the prevalence of underweight, overweight, and obesity.

Findings of the present study indicate the need for improving the nutritional status of adolescent girls. To improve nutritional status, various programs like adolescent health programme, Weekly IFA tablet Supplementation (WIFS), Rashtriya Kishor-Kishori Swasthya Karyakram (RKSK) and Poshan Abhiyan have been implemented. However, the present study showed poor uptake of these services. Various studies from Gujarat highlighted a high prevalence of underweight, ranging from $29.4 \%$ to $58.9 \%$ and poor service uptake of the health and nutrition services. ${ }^{29}$ Future studies should explore socio-cultural factors for lower malnutrition in Dev Bhumi Dwarka and understand barriers for adolescent girls in accessing nutritional and health services.

Various studies ${ }^{14,24,27,32-36}$ have reported a significant association of socio-demographic parameters like age, economic status, schooling status, family type, geographic locations, caste, knowledge, hygiene and sanitation practice with underweight. However, in the present study, only age, number of family members, knowledge, and use of toilet were statistically associated with BMI categories among adolescent girls. Although other factors were not statistically significant in the present study, their influence on the nutritional status of adolescent girls cannot be denied.

Adolescent nutrition should be prioritized with adequate improvement in the standards of living and timely health education. As Varma et $\mathrm{al}^{37}$ rightly pointed out, anemia is preventable disease and can be avoided by early screening and modification of diet. Thus, imparting knowledge about disease and its prevention should be made a thrust area in fight against anemia in adolescent. The fortification of diet along with supplementation of iron and folic acid for adolescent should be included in specific program in India. 
Table 6 Association of Socio-Demographic Parameters with Nutritional Status Among Adolescent Girls $(n=1240)$

\begin{tabular}{|c|c|c|c|c|c|}
\hline Parameters & $\begin{array}{l}\text { Underweight } \\
\left(<18.5 \mathrm{~kg} / \mathrm{m}^{2}\right)\end{array}$ & $\begin{array}{l}\text { Normal Weight (18.5- } \\
\left.22.9 \mathrm{~kg} / \mathrm{m}^{2}\right)\end{array}$ & $\begin{array}{l}\text { Overweight (23.0- } \\
\left.24.9 \mathrm{~kg} / \mathrm{m}^{2}\right)\end{array}$ & $\begin{array}{l}\text { Obese } \\
\left(\geq 25.0 \mathrm{~kg} / \mathrm{m}^{2}\right)\end{array}$ & $P$-value ${ }^{\$}$ \\
\hline & $\mathbf{N}$ & $\mathbf{N}$ & $\mathbf{N}$ & $\mathbf{N}$ & \\
\hline \multicolumn{6}{|l|}{ Age $(n=1240)$} \\
\hline 10 to 14 & 112 & 515 & 73 & 20 & \multirow[t]{2}{*}{$0.0002 * *$} \\
\hline 15 to 19 & $13 \mid$ & 339 & 37 & 13 & \\
\hline \multicolumn{6}{|l|}{ School status $(n=1240)$} \\
\hline School going & 162 & 564 & 70 & 18 & \multirow[t]{2}{*}{0.5375} \\
\hline Non-school going & 81 & 290 & 40 & 15 & \\
\hline \multicolumn{6}{|l|}{ Education $(n=1240)$} \\
\hline Illiterate & 9 & 34 & 5 & I & \multirow[t]{3}{*}{0.4529} \\
\hline Up to primary education & 103 & 363 & 38 & 9 & \\
\hline Secondary and higher education & $|3|$ & 457 & 67 & 23 & \\
\hline \multicolumn{6}{|l|}{ Type of family $(n=1240)$} \\
\hline Joint & 129 & 511 & 58 & 19 & \multirow[t]{2}{*}{0.1849} \\
\hline Nuclear & 114 & 343 & 52 & 14 & \\
\hline \multicolumn{6}{|l|}{ Caste $(n=1194)$} \\
\hline SC /ST & 40 & $|4|$ & 14 & 5 & \multirow[t]{3}{*}{0.3463} \\
\hline OBC & 163 & 519 & 79 & 17 & \\
\hline General & 38 & 153 & 16 & 9 & \\
\hline \multicolumn{6}{|l|}{ Religion $(n=1240)$} \\
\hline Hindu & 196 & 695 & 91 & 27 & \multirow[t]{3}{*}{0.5127} \\
\hline Muslim & 46 & 154 & 17 & 5 & \\
\hline Other & 1 & 5 & 2 & 1 & \\
\hline \multicolumn{6}{|l|}{ Family members $(n=1240)$} \\
\hline I & 4 & 15 & 4 & 2 & \multirow[t]{3}{*}{$0.01675^{*}$} \\
\hline 2 to 3 & 216 & 747 & 96 & 27 & \\
\hline 4 or more & 23 & 92 & 10 & 4 & \\
\hline \multicolumn{6}{|c|}{ Knowledge about Hemoglobin test $(n=1240)$} \\
\hline Yes & 55 & 259 & 40 & 13 & \multirow[t]{2}{*}{$0.02022 *$} \\
\hline No & 188 & 595 & 70 & 20 & \\
\hline \multicolumn{6}{|l|}{ Knowledge about malnutrition } \\
\hline Know & 37 & 103 & 29 & 8 & \multirow[t]{2}{*}{$0.0002^{* *}$} \\
\hline Do not know & 206 & 751 & 81 & 25 & \\
\hline
\end{tabular}


Table 6 (Continued).

\begin{tabular}{|c|c|c|c|c|c|}
\hline Parameters & $\begin{array}{l}\text { Underweight } \\
\left(<18.5 \mathrm{~kg} / \mathrm{m}^{2}\right)\end{array}$ & $\begin{array}{l}\text { Normal Weight (18.5- } \\
\left.22.9 \mathrm{~kg} / \mathrm{m}^{2}\right)\end{array}$ & $\begin{array}{l}\text { Overweight (23.0- } \\
\left.24.9 \mathrm{~kg} / \mathrm{m}^{2}\right)\end{array}$ & $\begin{array}{l}\text { Obese } \\
\left(\geq 25.0 \mathrm{~kg} / \mathrm{m}^{2}\right)\end{array}$ & $P$-value ${ }^{\$}$ \\
\hline & $\mathbf{N}$ & $\mathbf{N}$ & $\mathbf{N}$ & $\mathbf{N}$ & \\
\hline \multicolumn{5}{|c|}{ Knowledge about menstrual hygiene $(n=1240)$} & \\
\hline Know & 82 & 351 & 50 & 18 & \multirow[t]{2}{*}{$0.0358^{*}$} \\
\hline Do not know & 161 & 503 & 60 & 15 & \\
\hline \multicolumn{6}{|l|}{ Uptake of services $(n=\mid 240)$} \\
\hline Availed counselling & 117 & 439 & 65 & 17 & \multirow[t]{2}{*}{0.3039} \\
\hline Not availed counselling & 126 & 415 & 45 & 16 & \\
\hline Availed IFA \& calcium tablets & 102 & 377 & 45 & 13 & \multirow[t]{2}{*}{0.8294} \\
\hline Not availed IFA \& calcium tablets & 141 & 477 & 65 & 20 & \\
\hline Availed THR & 108 & 407 & 56 & 18 & \multirow[t]{2}{*}{0.5543} \\
\hline Not availed THR & 135 & 447 & 54 & 15 & \\
\hline $\begin{array}{l}\text { Availed anthropometry during } \\
\text { Mamta Diwas }\end{array}$ & 107 & 364 & 52 & 17 & \multirow[t]{2}{*}{0.6163} \\
\hline $\begin{array}{l}\text { Not availed anthropometry } \\
\text { during Mamta Diwas }\end{array}$ & 136 & 490 & 58 & 16 & \\
\hline \multicolumn{6}{|l|}{ Hygiene and sanitation } \\
\hline $\begin{array}{l}\text { Hand-washing in all critical } \\
\text { incidents }\end{array}$ & 44 & 148 & 13 & 4 & \multirow[t]{2}{*}{0.3853} \\
\hline $\begin{array}{l}\text { Not hand-washing in all critical } \\
\text { incidents }\end{array}$ & 199 & 705 & 97 & 30 & \\
\hline Use of toilet for defecation & 180 & 682 & 94 & 29 & \multirow[t]{2}{*}{$0.041 I^{*}$} \\
\hline Not using toilet for defecation & 63 & 172 & 16 & 4 & \\
\hline
\end{tabular}

Notes: ${ }^{{ }_{P}}$-value is of Chi-square test of independence. ${ }^{*}$ Significant at 0.05 level. $* *$ Significant at 0.01 level.

\section{Implications for Practices}

Adolescent girls in Devbhumi Dwarka district reported poor nutritional status, although comparatively lower than reported in previous studies from the state. Their nutritional status is likely to worsen during pregnancy, and may lead to complications or give a birth to low-birth weight babies, which ultimately create a vicious intergenerational cycle of malnutrition. The present study also reinforces a need for implementation research to identify barriers of lower uptake of health and nutrition services and enhance the reach of the current health and nutrition interventions.

Existing programs such as RKSK and Poshan Abhiyan provide a platform for screening all adolescents (school-going and non-school going, both girls and boys) that need to be strengthened to increase access, coverage, outreach, and utilization of services by adolescent girls in the district. Further, these programs record and monitor the nutritional status of adolescents in rural areas and hence offer scope for providing needbased timely counselling, treatment, and referral services. These opportunities should be leveraged by strengthening convergence between health and nutrition programs and enhancing health promotion and counselling efforts within existing interventions.

While national health programs broadly cover the main health issues in this population, local assessment of priorities and adaptation of program contents are necessary to ensure programs are relevant and effective. Thus, 
formative work to locally adapt the RKSK and Poshan Abhiyan Information, Education and Communication materials, training curriculum and implementation research is essential to optimize delivery of the intervention to different groups of adolescents.

\section{Conclusion}

The present study underscores the need for better nutrition and health interventions and implementation research to combat the problem of undernutrition among adolescent girls. Existing nutritional interventions need to focus on nutrition, health and hygiene education. Strengthening convergence between overarching health and nutrition programs may potentially improve the nutritional outcomes of adolescent girls. Implementation research should be encouraged to understand local barriers and enablers of effective program implementation.

\section{Acknowledgments}

The authors appreciate the support and co-operation received from Health Department, District Panchayat, Gujarat, for carrying out this study.

\section{Funding}

The authors declare that this study received funding from Nayara Energy. The funder had no role in study design, data collection and analysis, decision to publish, or manuscript preparation.

\section{Disclosure}

The authors report no conflicts of interest in this work.

\section{References}

1. World Health Organization. Recognizing adolescents. Available from: https://apps.who.int/adolescent/second-decade/section2/page1/recog nizing-adolescence.html. Accessed April 3, 2021.

2. UNICEF. Progress for children: a report card on adolescents. Socio-demographic profile of adolescents: UNICEF; 2012. 6. Available from: http://www.unicef.org/publications/files/Progress for_Children_No._10_EN_04232012.pdf. Accessed April 3, 2021.

3. Strategy Handbook. Rashtriya Kishor Swasthya Karyakram. Adolescent Health Division Ministry of Health and Family Welfare Government of India; 2014. Available from: https://www.dropbox. com/s/0oj4p422y7st4ku/RKSK\%20Strategy\%20Handbook.pdf. Accessed April 3, 2021.

4. World Health Organization. Adolescent health and development; 2020. Available from: https://www.who.int/news-room/q-a-detail/adolescenthealth-and-development. Accessed April 3, 2021.

5. Soliman A, De Sanctis V, Elalaily R, Bedair S. Advances in pubertal growth and factors influencing it: can we increase pubertal growth? Indian J Endocrinol Metab. 2014;18(Suppl1):S53-S62. doi:10.4103/ 2230-8210.145075
6. Savarino G, Corsello A, Corsello G. Macronutrient balance and micronutrient amounts through growth and development. Italian J Pediatr. 2021;47(1):1-4. doi:10.1186/s13052-021-01061-0

7. Christian P, Smith ER. Adolescent undernutrition: global burden, physiology, and nutritional risks. Ann Nutr Metab. 2018;72 (4):316-328. doi:10.1159/000488865

8. World Health Organization. Guideline: implementing effective actions for improving adolescent nutrition. Geneva: World Health Organization; 2018.

9. Jacob JA, Nair MK. Protein and micronutrient supplementation in complementing pubertal growth. Indian J Pediatr. 2012;79(Suppl 1): S84-91. doi:10.1007/s12098-011-0430-0

10. Ahmad S, Shukla NK, Singh JV, Shukla R, Shukla M. Double burden of malnutrition among school-going adolescent girls in North India: a cross-sectional study. $J$ Family Med Prim Care. 2018;7 (6):1417-1424. doi:10.4103/jfmpc.jfmpc_185_18

11. Rose-Clarke K, Pradhan H, Rath S, et al. Adolescent girls' health, nutrition and wellbeing in rural eastern India: a descriptive, crosssectional community-based study. BMC Public Health. 2019;19(1):1. doi:10.1186/s12889-019-7053-1

12. Caleyachetty R, Thomas GN, Kengne AP, et al. The double burden of malnutrition among adolescents: analysis of data from the global school-based student health and health behavior in school-aged children surveys in 57 low-and middle-income countries. Am J Clin Nutr. 2018;108(2):414-424. doi:10.1093/ajcn/nqy 105

13. UNICEF. Adolescent nutrition: investing in an age of opportunity to break cycles of poverty and inequity. Available from: https://www.unicef.org/ india/what-we-do/adolescent-nutrition. Accessed April 23, 2021.

14. Gupta A, Sharma D, Thakur D, Thakur A, Mazta SR. Prevalence and predictors of the dual burden of malnutrition among adolescents in North India. Saudi J Obesity. 2014;2:63-79. doi:10.4103/2347-2618.147345

15. International Institute for Population Sciences, and Macro International. National Family Health Survey (NFHS-4), 2015-16: India. 1. Mumbai: IIPS; 2016.

16. International Institute for Population Sciences. National Family Health Survey (NFHS-5), 2019-20: India. Mumbai: IIPS; 2021.

17. Hasan M, Sutradhar I, Shahabuddin A, Sarker M. Double burden of malnutrition among Bangladeshi women: a Literature review. Cureus. 2017;9:e1986. doi:10.7759/cureus.1986

18. Sivagurunathan C, Umadevi R, Rama R, Gopalakrishnan S. Adolescent health: present status and its related programmes in India? Are we in the right direction. J Clin Diagn Res. 2015;9: LE01-6. doi:10.7860/JCDR/2015/11199.5649

19. De Onis M, Onyango AW, Borghi E, Siyam A, Nishida C, Siekmann J. Development of a WHO growth reference for school aged children and adolescents. Bull World Health Organ. 2007;85:660-667. doi:10.2471/BLT.07.043497

20. Patton GC, Coffey C, Cappa C, et al. Health of the world's adolescents: a synthesis of internationally comparable data. Lancet. 2012;379(9826):1665-1675. doi:10.1016/S0140-6736(12)60203-7

21. United Nations. UN report; 2014.

22. Nair A, Doibale MK, Kuril BM, Domple VK. Study of nutritional status of adolescent girls in a rural area of a district of Maharashtra. Int J Community Med Public Health. 2017;4(12):4617-4622. doi:10.18203/2394-6040.ijcmph20175340

23. Konwar P, Vyas N, Hossain SS, Gore MN, Choudhury M. Nutritional status of adolescent girls belonging to the tea garden estates of Sivasagar district, Assam, India. Indian $J$ Community Med. 2019;44:238-242.

24. Dharmalingam A, Mena R, Raghupathy N, Sowmiya M. Cross sectional study on nutritional status and prevalence of anemia in rural adolescents. Int J Contemp Pediatr. 2017;4(3):951-955.

25 . NFHS-4 fact sheets for key indicators based on final data. India: National Family Health Survey. National Family Health Survey. Available from: http://www.rchiips.org/NFHS/factsheet_NFHS-4.shtml. Accessed April 23, 2021. 
26. Berhe K, Gebremariam G. Magnitude and associated factors of undernutrition (underweight and stunting) among school adolescent girls in Hawzen Woreda (District), Tigray regional state, Northern Ethiopia: cross-sectional study. BMC Res Notes. 2020;13(1):59. doi:10.1186/s13104-020-4926-4

27. Mohammed AY, Tefera TB. Nutritional status and associated risk factors among adolescents girls in Agarfa high school, Bale Zone, Oromia region, South East Ethiopia. Int $J$ Nutr Food Sci. 2015;4:445-452. doi:10.11648/j.ijnfs.20150404.15

28. Ministry of Health and Family Welfare (MoHFW), Government of India, UNICEF and Population Council. Comprehensive National Nutrition Survey (CNNS) National Report. New Delhi; 2019.

29. Trivedi PK, Saxena D, Puwar T, Yasobant S, Savaliya S, Fancy M. Assessment of nutritional status of adolescents: field experience from Rural Gujarat, India. Ntl J Community Med. 2016;7(12):926-930.

30. Pal A, Pari AK, Sinha A, Dhara PC. Prevalence of undernutrition and associated factors: a cross-sectional study among rural adolescents in West Bengal, India. Int J Pediatr Adolesc Med. 2017;4(1):9-18. doi:10.1016/j.ijpam.2016.08.009

31. Kulkarni R, Surve S, Patil S, Sankhe L, Gupta P, Toteja G. Nutritional status of adolescent girls in tribal blocks of Maharashtra. Indian $J$ Community Med. 2019;44:281-284. doi:10.4103/ijcm.IJCM_369_18

32. Young MF, Nguyen P, Avula R, Tran L, Menon P. Trends and determinants of low Body Mass Index (BMI) among 750,000 adolescents and women of reproductive age in India (P10-086-19). Curr Dev Nutr. 2019;3(Supplement1):nzz034-P10. doi:10.1093/cdn/ nzz034.P10-086-19
33. Das JK, Salam RA, Thornburg KL, et al. Nutrition in adolescents: physiology, metabolism, and nutritional needs. Ann N Y Acad Sci. 2017;1393(1):21-33. doi:10.1111/nyas.13330

34. Melaku YA, Zello GA, Gill TK, Adams RJ, Shi Z. Prevalence and factors associated with stunting and thinness among adolescent students in Northern Ethiopia: a comparison to World Health Organization standards. Arch Public Health. 2015;73(1):44. doi:10.1186/s13690-015-0093-9

35. Teferi DY, Atomssa GE, Mekonnen TC. Overweight and undernutrition in the cases of school-going adolescents in Wolaita Sodo Town, Southern Ethiopia: cross-Sectional Study. $J$ Nutr Metab. 2018;2018:8678561. doi:10.1155/2018/8678561

36. Assefa H, Belachew T, Negash L. Socioeconomic factors associated with underweight and stunting among adolescents of Jimma Zone, south west Ethiopia: a cross-sectional study. Int Sch Res Notices. 2013;2013. doi:10.1155/2013/238546

37. Varma A, Vagha J, Agrawal A, Meshram R, Damke S, Thakur S. Sociodemographic determinants in prevalence of anemia in adolescents of rural area of Maharashtra. J Datta Meghe Inst Med Sci Univ. 2020;15(2):209. doi:10.4103/jdmimsu.jdmimsu_179_20

\section{Publish your work in this journal}

Adolescent Health, Medicine and Therapeutics is an international, peer-reviewed, open access journal focusing on health, pathology, and treatment issues specific to the adolescent age group. All aspects of health maintenance, preventative measures and disease treatment interventions are addressed within the journal and practitioners from all disciplines are invited to submit their work as well as healthcare researchers and patient support groups. The manuscript management system is completely online and includes a very quick and fair peerreview system. Visit http://www.dovepress.com/testimonials.php to read real quotes from published authors. 